\title{
Interaction Between Sulfur and Iron in Plants
}

\author{
Stefania Astolfi ${ }^{*}$, Silvia Celletti ${ }^{1}$, Gianpiero Vigani ${ }^{2}$, Tanja Mimmo $^{3,4 *}$ and \\ Stefano $\mathrm{Cesco}^{3}$
}

${ }^{1}$ Department of Agricultural and Forestry Sciences (DAFNE), University of Tuscia, Viterbo, Italy, ${ }^{2}$ Department of Life Sciences and Systems Biology, Università degli Studi di Torino, Turin, Italy, ${ }^{3}$ Faculty of Science and Technology, Free University of Bozen-Bolzano, Bolzano, Italy, ${ }^{4}$ Competence Centre for Plant Health, Free University of Bozen-Bolzano, Bolzano, Italy

\section{OPEN ACCESS}

Edited by:

Francisco Javier Romera, University of Córdoba, Spain

Reviewed by:

Mohd Asgher,

Baba Ghulam Shah Badshah

University, India

Khurram Bashir,

Lahore University of Management

Sciences, Pakistan

*Correspondence:

Stefania Astolf

sastolfi@unitus.it

Tanja Mimmo

tanja.mimmo@unibz.it

Specialty section:

This article was submitted to

Plant Nutrition,

a section of the journal

Frontiers in Plant Science

Received: 20 February 2021

Accepted: 25 May 2021

Published: 20 July 2021

Citation:

Astolfi S, Celletti S, Vigani G,

Mimmo T and Cesco S (2021)

Interaction Between Sulfur and Iron

in Plants. Front. Plant Sci. 12:670308.

doi: 10.3389/fpls.2021.670308
It is well known that $S$ interacts with some macronutrients, such as $N, P$, and $K$, as well as with some micronutrients, such as $\mathrm{Fe}, \mathrm{Mo}, \mathrm{Cu}, \mathrm{Zn}$, and B. From our current understanding, such interactions could be related to the fact that: (i) $S$ shares similar chemical properties with other elements (e.g., Mo and Se) determining competition for the acquisition/transport process (SULTR transporter family proteins); (ii) S-requiring metabolic processes need the presence of other nutrients or regulate plant responses to other nutritional deficiencies (S-containing metabolites are the precursor for the synthesis of ethylene and phytosiderophores); (iii) S directly interacts with other elements (e.g., Fe) by forming complexes and chemical bonds, such as Fe-S clusters; and (iv) S is a constituent of organic molecules, which play crucial roles in plants (glutathione, transporters, etc.). This review summarizes the current state of knowledge of the interplay between $\mathrm{Fe}$ and $\mathrm{S}$ in plants. It has been demonstrated that plant capability to take up and accumulate Fe strongly depends on S availability in the growth medium in both monocots and dicot plants. Moreover, providing $S$ above the average nutritional need enhances the Fe content in wheat grains, this beneficial effect being particularly pronounced under severe Fe limitation. On the other hand, Fe shortage induces a significant increase in the demand for $\mathrm{S}$, resulting in enhanced $\mathrm{S}$ uptake and assimilation rate, similar to what happens under $S$ deficiency. The critical evaluation of the recent studies on the modulation of Fe/S interaction by integrating old and new insights gained on this topic will help to identify the main knowledge gaps. Indeed, it remains a challenge to determine how the interplay between $\mathrm{S}$ and $\mathrm{Fe}$ is regulated and how plants are able to sense environmental nutrient fluctuations and then to adapt their uptake, translocation, assimilation, and signaling. A better knowledge of the mechanisms of $\mathrm{Fe} / \mathrm{S}$ interaction might considerably help in improving crop performance within a context of limited nutrient resources and a more sustainable agriculture.

Keywords: iron, sulfur, interaction, methionine, nicotianamine, citrate

\section{INTRODUCTION}

The global human population is expected to increase to 9.7 billion by 2050 and 11.2 billion by 2100 (UN 2015). Thus, providing food and feed in an equitable, healthy, and sustainable manner is a key challenge (Beddington, 2010). The access to adequate and nutritious food is essential to human wellbeing, but to reach this objective global food production needs to be increased by $70 \%$ within 
2050. Healthy soil is a major factor for agriculture production, but soil resources are finite and non-renewable over the human time scale. Indeed, both natural events and mostly anthropogenic activities (e.g., deforestation, drainage, tillage, etc.) led to soil degradation and consequently to limited access to high-quality soil for provisioning of essential ecosystem services.

This negative trend is expected to continue at least until 2030 (Report: EU agricultural outlook 2017-30). Consequently, to maximize ecosystem services like food production, it is crucial to also recover the marginal agricultural lands for agriculture use. However, they have already been affected by the already existing problems of soil fertility (e.g., nutrient depletion, water scarcity, acidity, salinization, depletion of organic matter, and poor drainage) ascribable to the land-use changes (Scherr, 1999; Tilman et al., 2002; Lal, 2015), which have been often exacerbated by climate change (Pilbeam, 2015). It should also be highlighted that a more massive use of the current farming practices to meet the challenge of more food demand is very likely to lead to more intense competition for natural resources, increased greenhouse gas emissions, and further deforestation and land degradation. This condition is even more dramatic when comparing agricultural productivity between high-income and low-income countries.

The availability of nutrients in different edaphic conditions as well as its effect on the whole plant development and metabolism have been widely described, mainly at the level of a single nutrient at a time. However, at the field scale multiple deficiencies and/or nutrient interactions are very likely to occur. Furthermore, it is well recognized that the deficiency or excess of a single nutrient is typically coordinated with a change in the demand for another, or even more than one, nutrient. In this context, we can distinguish between positive/synergic interaction (when the plant grows better with combined nutrients with respect to the sum of their individual effects) and negative/antagonistic interaction (combining nutrients results in worsening plant growth with respect to the sum of their individual effects) (Fageria, 2001; Marschner, 2012; Pii et al., 2015; Rietra et al., 2017; Xie et al., 2021).

However, although the comprehension of the multi-level interactions among the various mineral elements is considered crucial to understanding the different sensing and signaling pathways induced by a single or multiple shortage/s, the impact of these nutrients' interactions on crop performance are largely unknown. This lack is certainly ascribable to the complexity of the phenomenon. In fact, the consequences of multiple deficiencies are almost never the mere sum of those caused by each of the individual deficiencies. An example is represented by the interactions between nitrogen $(\mathrm{N})$ and sulfur $(\mathrm{S})$. In this specific case, it has been widely demonstrated that grain productivity benefits from simultaneous $\mathrm{N}$ and $\mathrm{S}$ fertilization (Kalmbacher et al., 2005; Habtegebrial and Singh, 2006; Mathot et al., 2009; Salvagiotti et al., 2009), most likely for their role in protein synthesis (Crawford et al., 2000). In this respect, the coordination of $\mathrm{N}$ and $\mathrm{S}$ assimilatory pathways in plants corroborate this hypothesis, suggesting the functionality of putative co-regulation mechanisms (Koprivova et al., 2000). However, when one of the two nutrients is missing, the lacking one represses the assimilation of the other and induces physiological changes aiming at re-balancing the contents in the plant (Hawkesford and De Kok, 2006). Clear links have been also established between $\mathrm{S}$ and phosphorus (P) in the soil/plant system. Plants have developed tightly controlled mechanisms to coordinate $S$ transport and homeostasis with photosynthesis and the carbon status, in a similar manner to the inorganic $\mathrm{P}$ transport system (Lejay et al., 2008). Plants maintain intracellular homeostasis of both elements in response to their respective external availability. For instance, plant cells operate a rapid replacement of sulfolipids by phospholipids under S deficiency, and vice versa during $\mathrm{P}$ deficiency (Sugimoto et al., 2010). Such a metabolic switch is evidence of $\mathrm{P} / \mathrm{S}$ nutritional interdependency.

This review summarizes the current state in the field of the interplay between iron $(\mathrm{Fe})$ and $\mathrm{S}$ in plants toward a vision of a more sustainable use of the soil resource and within the context of the great challenge of food security.

\section{BASIS OF THE INTERACTION BETWEEN SULFUR AND IRON}

Over recent years, $\mathrm{S}$ deficiency has become widespread in many regions of the world. The occurrence of $S$ deficiency has been described in cereals as well as in other crops. The reasons behind this trend are mainly the strong decrease in the inputs of $S$ from atmospheric deposition and the use of high-analysis low S fertilizers (Zhao et al., 1999). At the beginning of the 1980s, environmental policies drastically reduced $\mathrm{SO}_{2}$ emissions with a further lowering in the 1990s (Haneklaus et al., 2008), causing a diminished $\mathrm{S}$ input to soil. This phenomenon has been worsened using high-analysis low-S fertilizers and the declining use of S-containing fungicides with the final result of a widespread S deficiency for crops (McGrath and Zhao, 1995; McGrath et al., 1996).

Iron deficiency is one of the major agricultural problems leading to lower crop yields and Fe fertilization management has been the focus of attention for the last decades (Kim and Guerinot, 2007; Briat, 2009). With respect to its metabolic roles, Fe nutrient is crucial for the proper functioning of metabolic processes related to electron transport, such as respiration and photosynthesis, as well as for chlorophyll biosynthesis (Briat et al., 2007). Indeed, Fe deficiency firstly appears with a reduced growth and leaf chlorosis in young leaves and then on older ones associated with alteration of the main metabolic pathways. Iron deficiency provokes serious imbalances in the ultrastructure and functionality of chloroplasts, with $90 \%$ of Fe present in a leaf localized in the chloroplasts (Morrissey and Guerinot, 2009; López-Millán et al., 2016).

In soils, $\mathrm{Fe}$ is present in huge amounts, being the fourth most abundant element in the earth's crust in percentage after oxygen, silicon, and aluminum. Therefore, widespread limited availability of Fe for plant nutrition is not related to its absolute content into the soil, but rather to its limited solubility. In particular, Fe deficiency is a typical feature of alkaline soils (Marschner, 2012), which cover more than $25 \%$ of the earth's surface (FAO, 2015). Low Fe availability in calcareous soils can be ascribed to 
an extremely low solubility of soil Fe. Further, alkaline conditions may also depress or even block Fe uptake mechanism from the apoplast into the symplast, which can be related to the $\mathrm{pH}$ of the former (Mengel, 1994; Nikolic and Kastori, 2000).

\section{SULFUR AVAILABILITY AFFECTS PLANT CAPABILITY TO COPE WITH IRON SHORTAGE}

When Fe is limited in the substrate, plant roots rely on two main strategies to acquire it, i.e., Strategy I and Strategy II, based on $\mathrm{Fe}^{3+}$-reduction and $\mathrm{Fe}^{3+}$-chelation, respectively (Kobayashi and Nishizawa, 2012). Strategy I, used by all except graminaceous plants, involves: (i) the mobilization of $\mathrm{Fe}^{3+}$ ions from soil particles through rhizosphere acidification, likely driven by an increase in plasma membrane $\mathrm{H}^{+}$-ATPase activity; (ii) the induction of a ferric chelate reductase (FCR) activity, which allows higher reduction rate of $\mathrm{Fe}^{3+}$ to $\mathrm{Fe}^{2+}$; and (iii) the uptake of the resulting $\mathrm{Fe}^{2+}$ via an $\mathrm{Fe}^{2+}$ transporter (IRT). The Strategy II system is restricted to grasses, which secrete mugineic acid (MA) family phytosiderophores (PS) from their roots to chelate and solubilize $\mathrm{Fe}^{3+}$ in the rhizosphere (Takagi, 1976). The $\mathrm{Fe}^{3+}$ PS complexes are then taken up by root cells through the action of Yellow Stripe 1 (YS1) proteins (Murata et al., 2006).

Both mechanisms undoubtedly improve Fe acquisition by plants, although Fe deficiency issues can still occur, regardless of whether the plant is being grown in nutrient-rich or poor soils. In fact, it has been observed that Fe deficiency could be caused by factors other than limited available Fe and, on the other hand, Fe deficiency could be overcome by factors besides Fe supply.

Research on the $\mathrm{S} / \mathrm{Fe}$ interaction started from the evidence that S-deficient plants showed a limited ability to accumulate Fe. Literature on this topic was minimal. In fact, to our knowledge, one of the first studies on barley plants showed that sulfate availability in Fe-deficient growth medium could affect PS accumulation in root tissues and the extent of ${ }^{14} \mathrm{C}$ glucose incorporation into PSs (Kuwajima and Kawai, 1997). Since then, significant interactions between external S supply and Fe homeostasis have been described in several crops, both grasses (Astolfi et al., 2003, 2006a, 2018; Bouranis et al., 2003; Zuchi et al., 2012; Ciaffi et al., 2013; Wu et al., 2015, 2020; Celletti et al., 2016a) and dicots (Zuchi et al., 2009, 2015; Muneer et al., 2014; Paolacci et al., 2014; Coppa et al., 2018), suggesting its independence of the adaptive responses activated by the plant species of both strategies.

Early physiological evidence showed that maize plants exposed to $\mathrm{S}$ deficiency had a lower shoot Fe content than those grown in the presence of S (Astolfi et al., 2003; Bouranis et al., 2003). Further, it has been demonstrated in barley that $S$ deficiency could potentially prevent Fe accumulation in shoots by lowering the release rate of PS (Astolfi et al., 2006a) and/or by hindering the capability to take up Fe from the external solution (Astolfi et al., 2006b). In addition, HvYS1 expression, the specific transporter of $\mathrm{Fe}^{3+}$-PS complexes, is modulated by $\mathrm{S}$ supply (Astolfi et al., 2010) in barley, suggesting that $S$ mainly affects the Fe acquisition step.
Interestingly, barley plants fully recovered their capability to cope with Fe shortage after resupplying $\mathrm{S}$ to $\mathrm{S}$-deficient plants (Astolfi et al., 2010, 2012). After the S resupply, the increase in PS release in root exudates was evident after $24 \mathrm{~h}$ of growth in S-sufficient nutrient solution and the increase reached values up to four-fold higher than control after $48 \mathrm{~h}$ from $\mathrm{S}$ resupply (Astolfi et al., 2010, 2012). A significant drop of Fe accumulation induced by $\mathrm{S}$ deficiency has been gathered in durum wheat (Ciaffi et al., 2013) and, later, in rice plants (Wu et al., 2015). Interestingly, transcriptomic analysis of durum wheat roots has identified 377 differentially expressed transcripts under S deficiency (Zamboni et al., 2017). Among them, several transcripts encoding formate dehydrogenase were downregulated by $\mathrm{S}$ deficiency, resulting in limited removal of the formate, which is released by the methionine (Met) cycle. As a result, the amount of NADH produced is not sufficient for PS biosynthesis, which is most likely hindered (Mori, 1999; Zamboni et al., 2017). On the other hand, it has been recently shown that S-deficiency-induced reduction of $\mathrm{Fe}$ content in rice shoots was associated to a decreased nicotianamine (NA) level, suggesting that $\mathrm{S}$ is not only crucial for Fe acquisition but also for its translocation to the shoot (Wu et al., 2020), being NA the main Fe chelator involved in both xylem and phloem Fe transport within the plants (Von Wirén et al., 1999; Briat et al., 2007).

Overall, this evidence indicated that plants require an adequate $S$ supply to efficiently cope with Fe starvation. Thus, it was not surprising that an over-supply of $S$ allowed to improve, specifically in durum wheat, the Fe use efficiency of plants and the accumulation of this micronutrient in plant tissues (Zuchi et al., 2012; Celletti et al., 2016a). Moreover, providing S above adequate concentrations may result in the improvement of wheat Fe use efficiency (Hawkesford et al., 2014) and this S nutritional effect seems to be especially advantageous for plants grown under severe Fe limitation, leading to a significant recovery of deficiency symptoms (Zuchi et al., 2012). However, the positive effect of super-optimal S supply in improving the capability of wheat plants to accumulate Fe was later confirmed in wheat but not in barley and maize plants. In these an antagonistic effect between Fe deficiency and S surplus has been observed, resulting in a reduction of $\mathrm{Fe}$ accumulation in shoots (Celletti et al., 2016a). The differential Fe accumulation pattern could most likely be ascribed to the different capability to release PS by the three grasses (Marschner, 2012). Actually, the increased ability of durum wheat to accumulate $\mathrm{Fe}$ was associated with a significantly higher PS release at root level, but the same did not hold true for barley and maize (Celletti et al., 2016a). Interestingly, PS release from wheat roots was also associated with increased $\mathrm{S}$ accumulation in both shoot and root tissues (Celletti et al., 2016a).

This aspect of $\mathrm{S} / \mathrm{Fe}$ interplay highlights new solutions to increase $\mathrm{Fe}$ levels in cereal grains and might be exploited for biofortification purposes. Unfortunately, increased $\mathrm{Fe}$ accumulation in vegetative tissues resulting from super-optimal $S$ supply did not result in increased Fe concentration in grains, suggesting that the mechanisms involved in the allocation of $\mathrm{Fe}$ in seeds might be different from those controlling the root uptake and the allocation in the leaves (Astolfi et al., 2018). 
However, S over-fertilization allowed plants to at least overcome Fe deficiency (Astolfi et al., 2018).

On the other hand, the reduction of shoot Fe concentration induced by limited S supply was also observed in dicots, such as tomato (Zuchi et al., 2009) and oilseed rape (Muneer et al., 2014). In S-deficient tomato plants it has been ascribed to the inhibition of $\mathrm{Fe}$ uptake, due to the prevented induction of the $\mathrm{Fe}^{3+}$-chelate reductase and the limited activity and expression of the $\mathrm{Fe}^{2+}$ transporter (IRT1), also associated to a reduced translocation of $\mathrm{Fe}$ to the shoot, as shown by abolished expression of the NA synthase (LeNAS) gene (Zuchi et al., 2009). These findings suggested that an adequate $S$ availability is needed to sustain the ethylene (ET) and NA biosynthetic pathways (Zuchi et al., 2009). Quite different behavior on exposure to $\mathrm{S}$ deficiency was found for oilseed rape, which exhibited an upregulation of IRT1 and FRO1 in the earlier phase. However, the expression of both genes and FCR activity decreased in the later phases, in agreement with Zuchi et al. (2009) (Muneer et al., 2014).

Now, it is well established that the abolished expression of SINAS gene following $S$ deficiency condition effectively resulted in reduced NA levels in tomato (Zuchi et al., 2015). In addition, it has been observed that the two components of the Fe deficiency response (reduction and transmembrane transport) are differentially sensitive to or regulated by ET levels, confirming and extending previous findings in tomato (Zuchi et al., 2009). This is strongly evident considering that ET levels seem to stimulate the components of the Fe deficiency response: the expression of FIT (FER), the ability to acidify the external medium with regulation of plasma membrane $\mathrm{H}^{+}$ATPase (Lucena et al., 2015), and the reduction of ferric Fe (Romera and Alcántara, 2004). However, increased root ET production following imposition of S deficiency only significantly affected the expression of SIIRT1 (Zuchi et al., 2015). It has been suggested that $S$ deficiency can result in the induction of the ET pathway (Wawrzynska et al., 2015). Ethylene biosynthesis is indeed related to $S$ through the formation of S-containing metabolites in the $\mathrm{S}$ assimilatory pathway such as cysteine (Cys), Met, and S-adenosylmethionine (SAM) (Khan et al., 2016). Ethylene and $S$ operate interdependently in regulating plant adaptation processes and abiotic stress tolerance in both optimal and stress environmental growth conditions (Iqbal et al., 2013).

Although these findings account for the hampered capability of dicots to cope with the $\mathrm{Fe}$ nutritional disorder under the simultaneous imposition of $S$ deficiency, the question remains, however, whether plant $\mathrm{S}$ status and/or S external concentration could modify the capability to take up and accumulate Fe. This challenge has been highlighted recently by Coppa et al. (2018) using a split-root approach, showing that both SlFER and SlFRO1 expression, and $\mathrm{Fe}^{3+}$-reducing activity, were induced in the portion of the root system subjected to combined $S$ and Fe deficiency compared to the portion of the root subjected only to Fe deficiency. In addition, it was again confirmed that distinct regulatory processes target SlFRO1 and SIIRT1, since the expression of this latter did not change between the two separated portions of the root system (Coppa et al., 2018). In particular, it was suggested that SIIRT1 might be controlled by regulatory mechanisms more complex with respect to SlFRO1 (Coppa et al., 2018).

\section{IRON DEFICIENCY MODULATES SULFUR UPTAKE AND ASSIMILATION RATE}

Sulfur is present in soils in different oxidation states (from -2 of sulfide $\mathrm{S}^{2-}$ to +6 of sulfate $\mathrm{SO}_{4}{ }^{2-}$ ) (Lewandowska and Sirko, 2008). Plants can use sulfur dioxide $\left(\mathrm{SO}_{2}\right)$ through open stomata but sulfate taken up by roots represents the most important source of S for plants (Marschner, 2012). Sulfate transport across the plasma membrane into the root cells is a secondary active transport system with energy consumption (obtained from ATP hydrolysis) and coupled with protons (at least $3 \mathrm{H}^{+}$per $\mathrm{SO}_{4}{ }^{2-}$ ) (Clarkson et al., 1993). Both sulfate uptake from soil and its distribution within plant requires specific transporters, which have been isolated, characterized, and divided into five groups (Buchner et al., 2004).

Once inside roots, sulfate is first reduced and then incorporated into organic compounds (Hawkesford, 2000; Leustek et al., 2000). Both reduction and assimilation mainly occur in leaf tissues since the enzymes involved in these processes are localized in chloroplasts (and, to a lesser extent, in root plastids) (Feldman-Salit et al., 2019). The assimilatory pathway of sulfate starts with sulfate activation, catalyzed by the enzyme ATP sulfurylase (ATPS) which produces adenosine $5^{\prime}$-phosphosulfate (APS), which in turn is reduced to sulfite $\left(\mathrm{SO}_{3}{ }^{2-}\right)$ by the activity of APS reductase (APR) with glutathione (GSH) as electron donor. Sulfite is then reduced to sulfide $\left(\mathrm{S}^{2-}\right)$ by the enzyme sulfite reductase (SiR). The first stable compound of $S$ assimilation pathway is the amino acid Cys, synthesized by condensation of $O$-acetylserine (OAS) (produced by the activity of serine acetyl-transferase, SERAT) and $S^{2-}$ in the reaction catalyzed by $\mathrm{O}$-acetylserine-(thiol)lyase (OAS-TL) (Hatzfeld et al., 2000; Leustek et al., 2000; Kopriva, 2006; Lewandowska and Sirko, 2008; Koprivova and Kopriva, 2014).

The second S-containing amino acid, Met, is synthesized in three steps using as precursor Cys. In the first step, the enzyme cystathionine- $\gamma$-synthase (CGL) catalyzes cystathionine production from $\mathrm{Cys}$ and $\mathrm{O}$-phosphoserine $(\mathrm{OPH})$, which derives from aspartate. An $\alpha, \beta$-elimination of cystathionine is determined by the subsequent activity of cystathionine- $\beta$-lyase $(\mathrm{CBL})$, which catalyzes the penultimate step in the biosynthesis of Met, in which cystathionine is cleaved to produce homocysteine (homo-Cys), pyruvate, and ammonia (Ravanel et al., 1998; Saito, 2000). In the last step, a methyl group from $\mathrm{N}^{5}$-methyltetrahydrofolate $\left(5-\mathrm{CH}_{3} \mathrm{H}_{4} \mathrm{PteGlu}_{\mathrm{n}}\right)$ is transferred to homo-Cys by the cobalamin-independent Met synthase (MS), producing tetrahydrofolate and Met (Ravanel et al., 1998). Methionine is then incorporated into proteins or converted to SAM by SAM synthetase (SAMS) (Hoefgen and Hesse, 2007; Amir, 2010; Jobe et al., 2019).

$S$-adenosylmethionine is the precursor of ET, biotin, polyamines, NA, and many other secondary metabolites, such as 
PS. Moreover, SAM is the key substrate of different enzymes and the methyl donor in RNA and DNA modification.

Cysteine is also the precursor of the tripeptide glutathione ( $\gamma$-glutamylcysteinglycin, GSH), which is synthesized in two ATP-dependent steps (Hoefgen and Hesse, 2007; North and Kopriva, 2007; Takahashi et al., 2011; Jobe et al., 2019). Firstly, $\gamma$-glutamylcysteine synthetase (ECS) catalyzes the synthesis of $\gamma$-glutamylcysteine $(\gamma$-EC) from L-glutamate and L-Cys, then GSH synthetase (GSHS) catalyzes the addition of glycine to the C-terminus to form GSH, which is the main form of reduced $S$ in the phloem. Finally, Cys seems to also be the S-donor for Fe/S-cluster synthesis (Balk and Lobréaux, 2005). Other S-compounds are produced through an alternative pattern in which APS can be phosphorylated by the APS kinase (APSK) with the formation of adenosine 3'-phosphate 5'-phosphosulfate (PAPS), which is used as a precursor by the multiprotein family of sulfotransferases (SOTs) for the synthesis of coumarins, glucosinolates, flavonoids, gibberellic acids, hydroxyjasmonates, phenolic acids, steroids, or sulfate esters (Klein and Papenbrock, 2004; Lewandowska and Sirko, 2008).

Sulfate uptake, translocation, and assimilation require tight and coordinated regulation, which is achieved by both induction and repression. For instance, $\mathrm{S}$ deficiency in the growth medium commonly causes an increase in uptake rate, by upregulation of transporters, whereas the accumulation of S-containing compounds in plant cells inhibits uptake rate by downregulation of sulfate transporters (Hawkesford, 2003).

In addition to $S$ availability, other factors are able to positively or negatively modulate S metabolism, such as heavy metals (Astolfi et al., 2004b, 2014; Yamaguchi et al., 2016; Ma et al., 2018).

Recently, it has been highlighted that one of the most striking adaptations to $\mathrm{Fe}$ shortage in plants relies on the plant ability to modulate sulfate uptake and assimilation rates (Astolfi et al., 2004a, 2006b; Ciaffi et al., 2013; Paolacci et al., 2014). Overall, Fe deficiency induces a significant increase in the demand for $S$, and thus activates $S$ uptake and assimilation rate similarly to $\mathrm{S}$ deficiency condition. In particular, $\mathrm{Fe}$ deficiency increased ${ }^{35} \mathrm{SO}_{4}{ }^{2-}$ uptake rates by maize and barley roots (Astolfi et al., 2004a, 2006b). Furthermore, Fe deficiency affected the partitioning from the shoots to the roots of reduced $S$ pool within the plant: barley plants exhibited an increased root Cys concentration (Astolfi et al., 2006b), whereas tomato plants showed an increased root-to-shoot translocation of thiols (Paolacci et al., 2014).

Iron availability modulates the expression level of genes involved in both uptake and assimilation of sulfate in grasses, such as barley and durum wheat (Astolfi et al., 2012; Ciaffi et al., 2013), as well as in tomato (Paolacci et al., 2014; Zuchi et al., 2015).

In particular, the expression of the high-affinity sulfate transporter TdSultr1.3 was significantly induced by Fe deficiency both in shoots and roots of durum wheat plants, as well as most of the genes of the $\mathrm{S}$ assimilatory pathway (i.e., TdATPSul1, TdAPR, TdSir, TdSAT1, and TdSAT2) (Ciaffi et al., 2013). On the other hand, the expression of most of the tomato sulfate transporter genes, belonging to Group 1 (SIST 1.1 and 1.2), 2 (SIST 2.1), and 4 (SlST 4.1), was significantly up-regulated in Fe-deficient roots (Paolacci et al., 2014).

Recently, the dose-response effect in the activation of the adaptive mechanisms in durum wheat has been characterized, and the minimum level of Fe availability (i.e., an Fe concentration threshold) triggering the quite expensive response has been identified. In this respect, it has been demonstrated that there is an Fe-availability threshold $(25 \mu \mathrm{M})$ below which a complex reorganization of $\mathrm{S}$ metabolism (and allocation) is required to guarantee an efficient plant response to the nutritional disorder. This hypothesis is supported by the increase of root ATPS activity, followed by the enhancement of both leaf ATPS and root OASTL activities and the rise of shoot thiols concentrations. It is evident that this process is very expensive and, when activated, could have detrimental consequences on biomass accumulation, thus limiting crop yields as well as weakening the grain quality (Celletti et al., 2016b).

\section{WHAT ARE THE REASONS FOR THE CROSSTALK BETWEEN SULFUR AND IRON NUTRITION? ARE THERE COMMON SIGNALS INVOLVED IN THEIR HOMEOSTASIS?}

The description of both Fe acquisition systems indicates that the amino acid Met could reasonably represent the first connection between Fe and S, since ET, NA, and PS biosynthesis feed on a common precursor, SAM (Hesse and Hoefgen, 2003; Bürstenbinder et al., 2007). The coexistence of traits of both strategies in crossed-form between monocots and dicots (Astolfi et al., 2020) further corroborates this hypothesis (Figure 1A).

Ethylene plays a key role in many processes, such as root hair development, fruit ripening, and seed germination (Wang et al., 2002; Corbineau et al., 2014; Khan et al., 2017). Furthermore, together with jasmonic acid and salicylic acid, ET seems to be involved in abiotic and biotic stress responses (Wang et al., 2002; Yang et al., 2019). More importantly, it has been shown that ET biosynthesis increases under Fe deficiency at root level and is closely correlated with $\mathrm{Fe}^{3+}$-reducing capacity (Romera et al., 1999).

Phytosiderophores are secreted by the roots of grasses into the rhizosphere, where PS can form stable complexes with cationic micronutrients, such as $\mathrm{Fe}^{3+}$. The most common PS are mugineic acid (MA), deoxymugineic acid (DMA) and epi-hydroxymugineic acid (epi-HMA). Mori and Nishizawa (1987) identified the S-containing amino acid Met as their sole precursor.

The distribution of Fe within the plant is mainly governed by NA (Rudolph et al., 1985; Douchkov et al., 2002; Takahashi et al., 2003).

Based on this evidence, the interplay could be ascribed to a decrease in the production and release of PS induced by $S$ deficiency in grasses, whereas to an impaired ET and NA production in tomato (Figure 1A). 


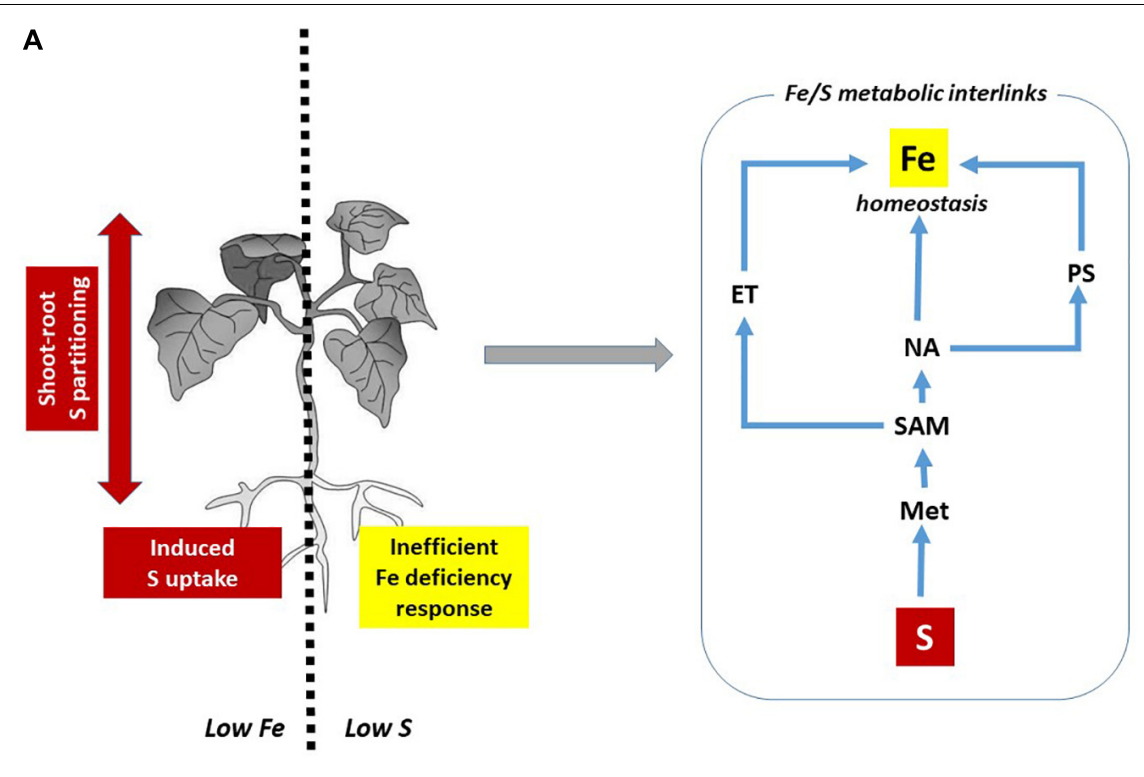

B

Early responses

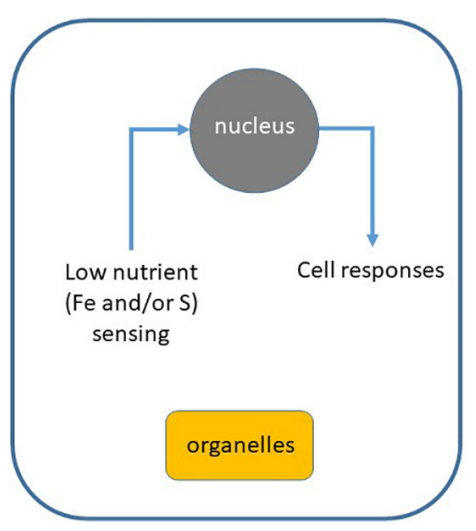

Late responses

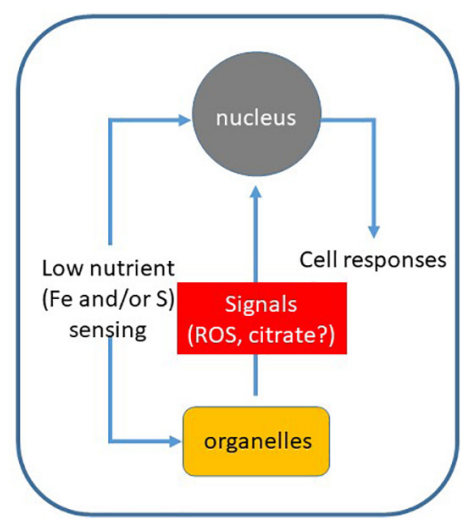

FIGURE 1 | Overview of Fe and S Interaction in plants. (A) In plants, Fe and S availability affect S and Fe homeostasis, respectively (left panel, see text for details). The metabolic interlinks between Fe and $\mathrm{S}$ seem to be related to the biosynthesis of specific compounds: $\mathrm{S}$ is essential for Met synthesis, the pivotal precursor of ET, NA, and PS through the SAM biosynthesis pathway (right panel). (B) Hypothetical involvement of organelles (such as mitochondria) in the modulation of Fe and S deficiency-induced responses. The engagement of specific cellular sensing and signaling pathways might depend on the progression/severity degree of nutrient deficiency. Mitochondria impairment might be a source of still unknown signals (likely ROS and/or citric acid) able to modulate cellular responses. ET, ethylene; Met, methionine; NA, nicotianamine; PS, phytosiderophore; SAM, S-adenosylmethionine.

It has been clearly demonstrated that $\mathrm{S}$ limited availability hinders plant capability to take up and accumulate $\mathrm{Fe}$ by decreasing PS release rate in grasses (Bouranis et al., 2003; Astolfi et al., 2006a; Zuchi et al., 2012; Celletti et al., 2016a) and by inhibiting ET and NA biosynthesis in dicots (Zuchi et al., 2009, 2015). In this respect, and specifically considering grasses, the altered PS release induced by the onset of the xenobiotic detoxification metabolism (Del Buono et al., 2015; Bartucca et al., 2017a,b), which mainly depends on S metabolites, further supports the hypothesis of the relevance of the $S$ pools in plants for an appropriate response to $\mathrm{Fe}$ shortage.
Furthermore, it has been suggested that limited availability of $S$ could impact the Fe metabolism for its effect on Met synthesis. Under Fe deficiency, Strategy I plants increase ET and NA synthesis (Li and Li, 2004; Molassiotis et al., 2005; Zuchi et al., 2009) with relevant consumption of Met, which represents the precursor of both compounds (Hesse and Hoefgen, 2003), and the same could occur in Strategy II plants, in which Met is the precursor of PS (Guerinot and Yi, 1994). Consequently, the observed regulation of $S$ uptake by roots and root-to-shoot translocation rate might be explained by the need to meet the increased demand for Met and its 
derivatives in response to Fe starvation (Zuchi et al., 2009, 2015; Paolacci et al., 2014).

However, higher S needs to sustain the activation of Strategy I and II mechanisms cannot fully account for the responses to combined S/Fe deficiency observed in plants.

For example, Fe limitation in wheat plants under adequate $S$ nutrition produced a $S$ deficiency-like response at the molecular level, resulting in higher expression of genes encoding highaffinity sulfate transporters. However, under S deficiency sulfate uptake, capacity of the roots was increased by the upregulation of TdSultr1.1, whereas under Fe deficiency it occurred through the upregulation of TdSultr1.3, highlighting that the mechanism at the base of the sulfate uptake modulation by Fe or S deficiency might be different (Ciaffi et al., 2013). On the other hand, in tomato plants the transcriptional level of SIIRT1, encoding the Fe transporter involved in $\mathrm{Fe}^{2+}$ uptake from the soil, in roots exposed to both $\mathrm{Fe}$ and $\mathrm{S}$ deficiency was approximately seven times higher than in control plants, which corresponded to the sum of the transcript increases observed in the -Fe (five times higher than in control plants) and -S (about two-fold higher than in control plants) plants. This finding suggests that IRT1 gene expression could be regulated by complex mechanisms that might differ from Fe supply. Several factors regulating the IRT1 expression at a post-translational level have been identified and characterized in recent years (Shin et al., 2013; Ivanov et al., 2014). In Arabidopsis thaliana, IRT1 acts as metal transceptor critical for optimal Fe and non-Fe metal homeostasis (Dubeaux et al., 2018). In particular, these authors demonstrated that IRT1 transporters are able to perceive metal excess (for instance $\mathrm{Mn}$ and $\mathrm{Zn}$ ) and to address IRT1 to protein degradation.

Recently, Robe et al. (2020) showed that, in Arabidopsis thaliana, the $S$ deficiency-mediated negative regulation of the Fe uptake machinery might be induced to limit the unspecific transport into the root of potentially toxic divalent cations such as Mn and Zn by IRT1 (and other transporters like NRAMP1). Such findings highlight the importance to investigate the regulation of $\mathrm{Fe} / \mathrm{S}$ interplay by considering the interaction of both Fe and S also with other essential nutrients.

Thus, it is reasonable to suggest a direct interference of $\mathrm{Fe}$ with the signal transduction pathway involved in $\mathrm{S}$ metabolism (and vice versa), and with the activation of different acquisition strategies.

On the other hand, Fe-S clusters' assembly has emerged as a further important link between $\mathrm{S}$ and Fe (Balk and Pilon, 2011; Mapolelo et al., 2013; Balk and Schaedler, 2014), even if there is no information about the coordination between the assembly of Fe-S clusters and the assimilation pathways of $\mathrm{S}$ and Fe. These clusters are the most ubiquitous and versatile prosthetic groups (Pala et al., 2018) and their biogenesis involves three different assembly machineries: SUF machinery located in chloroplast, the Fe-S cluster (ISC) assembly machinery in mitochondria, and the cytosolic Fe-S protein assembly (CIA) machinery located in cytosol (Balk and Schaedler, 2014). In particular, mitochondrion and the ISC has a central role, since this machinery matures all organellar $\mathrm{Fe}-\mathrm{S}$ protein and provides an unknown S-containing compound, translocated by an $\mathrm{ABC}$ transporter into the cytosol, that is necessary for the extramitochondrial Fe-S protein maturation (Stehling and Lill, 2013). However, the evidence that both nutrients are needed for Fe-S cluster biosynthesis, even explaining reduced Fe uptake under $S$ deficiency, does not explain increased $S$ uptake and assimilation under Fe deficiency, suggesting the existence of unknown regulation/signaling mechanisms involved in their close interplay.

All these pieces of evidence seem to support a model in which Fe and S metabolism need to be coordinated, at least up to a certain level, so as to guarantee an adequate formation of the Fe$\mathrm{S}$ clusters. On the other hand, having $\mathrm{S}$ metabolism additionally involved in multiple steps of primary and secondary metabolism, an independent form of modulation between the metabolism of the two nutrients, cannot be completely excluded.

At least in part, this hypothesis is mirrored by the intensive overlapping concurrently to a series of distinct responses observed by using metabolome (in tomato, Zuchi et al., 2015) and transcriptome-wide (in wheat, Zamboni et al., 2017) approaches to study the $\mathrm{S} / \mathrm{Fe}$ interplay.

The potential role of citric acid in plant-adaptation to $\mathrm{Fe}$ deficiency and combined S and Fe deficiency has been recently suggested (Coppa et al., 2018; Vigani et al., 2018). The rationale for such an explanation has been that citric acid is produced in mitochondria, where the assembly of Fe-S clusters also occurs (Balk and Pilon, 2011). However, the role of both citrate and retrograde signaling in such regulating process still remains to be elucidated, as recently reviewed by Mendoza-Cózatl et al. (2019). To disentangle the involvement of organelles-nucleus communication in the $\mathrm{Fe} / \mathrm{S}$ interplay, a broader interaction among nutrients should be considered. Indeed, mitochondria as well as chloroplasts are important cellular sites where complex nutrient interactions take place (Vigani and Hanikenne, 2018; Courbet et al., 2019).

\section{CONCLUDING REMARKS}

Identifying a suitable approach to unravel the mechanism underling the $\mathrm{Fe} / \mathrm{S}$ interplay still remains challenging. The complex regulation of both $\mathrm{Fe}$ and $\mathrm{S}$ homeostasis involves different regulating pathways with likely different signal molecules (Wawrzyñska and Sirko, 2020). Such complexity relies mainly on the following aspects: (i) different regulating mechanisms might act at local (cell and/or tissue) and systemic level (shoot-root communication); and (ii) nutrient deficiencyinduced responses of plants are tailored on the harshness degree of stress.

Due to the high Fe and S demand for both mitochondria and chloroplasts, at the cellular level particular interest has been devoted to the role of retrograde signaling pathway in the regulation of $\mathrm{Fe}$ - and S-responsive genes. It has been observed that mitochondrial dysfunction displayed alteration of such genes (Vigani and Briat, 2016). Although some indirect evidence suggested that citrate might be involved in the organelles-nucleus communication, signal molecules involved in such pathway under Fe and S deficiency are still not known. As reviewed by Mendoza-Cózatl et al. (2019), the oxidative stress and, in turn, 
ROS signaling, might drive retrograde pathway during $\mathrm{Fe}$ and $\mathrm{S}$ deficiency, since the ROS generated in the Arabidopsis thaliana mutants with diverse mitochondrial dysfunction phenotypes might be responsible for the transcriptional reprogramming observed across mutants (Schwarzländer et al., 2012). The transcriptomic analysis of such mutants revealed that the expression of several Fe- and S-responsive genes was affected in plants showing an induced mitochondrial dysfunction (Vigani and Briat, 2016), highlighting that a link between mitochondrial impairment and $\mathrm{Fe}$ and $\mathrm{S}$ homeostasis would be possible. However, if such regulation occurs directly or indirectly from mitochondria, still remains to be elucidated.

The severity degree of nutrient deficiency also requires different regulating mechanisms depending on stress phases perceived by plants (Vigani and Murgia, 2018). The progression of $\mathrm{Fe}$ deficiency perception occurs through three different phases: (i) the alarm stress (referring to the homeostatic control of nutrients content), (ii) the resistance stress (when plant growth starts to be impaired), and (iii) the exhaustion phase (when severe and prolonged deficiency determines growth retardation and death). Such different stress phases involve the engagement of different plant responses. Most likely, such stress progression patterns might also occur for other nutrients, such as $\mathrm{S}$. Therefore, in order to discriminate the molecular actors responsible for $\mathrm{Fe} / \mathrm{S}$ interplay it is important to identify which step of stress the plants are facing. In this contest, organelles such as mitochondria could play a role in modulation of cellular responses showing different patterns in relation to different severity degrees of nutrient deficiency (Figure 1B).

In conclusion, the analysis of the scientific literature concerning plant mineral nutrition also reported in the present review, clearly shows that the comprehension of the adaptive responses of plants/crops to the nutrient fluctuations in soil have had a notable development in recent years. However, despite the undoubted progress in knowledge, these pieces of information seem to be too limited to fully understand and then to contribute to setting up appropriate agronomical practices for more complex edaphic conditions where more than one single nutrient/element of fertility is concurrently the cause of

\section{REFERENCES}

Amir, R. (2010). Current understanding of the factors regulating methionine content in vegetative tissues of higher plants. Amino Acids 39, 917-931. doi: 10.1007/s00726-010-0482-x

Astolfi, S., Cesco, S., Zuchi, S., Neumann, G., and Roemheld, V. (2006a). Sulfur starvation reduces phytosiderophores release by iron-deficient barley plants. Soil Sci. Plant Nutr. 52, 43-48. doi: 10.1111/j.1747-0765.2006.00 010.x

Astolfi, S., Ortolani, M. R., Catarcione, G., Paolacci, A. R., Cesco, S., Pinton, R., et al. (2014). Cadmium exposure affects iron acquisition in barley (Hordeum vulgare) seedlings. Physiol. Plant. 152, 646-659. doi: 10.1111/ppl. 12207

Astolfi, S., Pii, Y., Mimmo, T., Lucini, L., Miras-Moreno, M. B., Coppa, E., et al. (2020). Single and combined fe and s deficiency differentially modulate root exudate composition in tomato: a double strategy for fe acquisition? Int. J. Mol. Sci. 21:4038. doi: 10.3390/ijms21114038 the (nutritional) stress. Moreover, this aspect appears even more important when the need for an adequate reserve of one nutrient for an appropriate response to the shortage of another one is also considered. A clear example in this sense is represented by $\mathrm{Fe}$ and $\mathrm{S}$ interplay. The increasing frequency of these cases at the field level, in particular in marginal soils, and the need to rely on all arable land to overcome the challenge of food demand and security, urge researchers to proceed with this methodological approach focused on soil-root system in its integrity and complexity, including the reciprocal interactions among different nutrients. It is definitely complicated but the non-additivity of the adaptive crop responses to each nutrient seems to highlight its strategic nature. Moreover, the transition toward sustainability that characterizes the entire agricultural production system of our time cannot ignore a better and more defined understanding of the phenomena underlying the soilplant interactions at the rhizosphere that are crucial for the best use of the endogenous nutrient soil resources while preserving its fertility in the long period.

\section{AUTHOR CONTRIBUTIONS}

SA was responsible for drafting of the manuscript and edited the manuscript. SiC, GV, TM, and StC took part in draft preparation. All authors have read and agreed to the published version of the manuscript.

\section{FUNDING}

The research was carried out in the frame of the MIUR (Ministry of Education, University and Research) initiative "Department of Excellence" (Law 232/2016).

\section{ACKNOWLEDGMENTS}

This work was supported by the Open Access Publishing Fund of the Free University of Bozen-Bolzano.

Astolfi, S., Pii, Y., Terzano, R., Mimmo, T., Celletti, S., Allegretta, I., et al. (2018). Does Fe accumulation in durum wheat seeds benefit from improved wholeplant sulfur nutrition? J. Cereal Sci. 83, 74-82. doi: 10.1016/j.jcs.2018.07.010

Astolfi, S., Zuchi, S., Cesco, S., Sanità di Toppi, L., Pirazzi, D., Badiani, M., et al. (2006b). Iron deficiency induces sulfate uptake and modulates redistribution of reduced sulfur pool in barley plants. Funct. Plant Biol. 33:1055. doi: 10.1071/ FP06179

Astolfi, S., Zuchi, S., Cesco, S., Varanini, Z., and Pinton, R. (2004a). Influence of iron nutrition on sulphur uptake and metabolism in maize (Zea mays L.) roots. Soil Sci. Plant Nutr. 50, 1079-1083. doi: 10.1080/00380768.2004.1040 8577

Astolfi, S., Zuchi, S., Hubberten, H.-M., Pinton, R., and Hoefgen, R. (2010). Supply of sulphur to S-deficient young barley seedlings restores their capability to cope with iron shortage. J. Exp. Bot. 61, 799-806. doi: 10.1093/jxb/erp346

Astolfi, S., Zuchi, S., Neumann, G., Cesco, S., Di Toppi, L. S., and Pinton, R. (2012). Response of barley plants to Fe deficiency and Cd contamination as affected by S starvation. J. Exp. Bot. 63, 1241-1250. doi: 10.1093/jxb/err344 
Astolfi, S., Zuchi, S., and Passera, C. (2004b). Role of sulphur availability on cadmium-induced changes of nitrogen and sulphur metabolism in maize (Zea mays L.) leaves. J. Plant Physiol. 161, 795-802. doi: 10.1016/j.jplph.2003. 11.005

Astolfi, S., Zuchi, S., Passera, C., and Cesco, S. (2003). Does the sulfur assimilation pathway play a role in the response to fe deficiency in Maize (Zea mays L.) Plants? J. Plant Nutr. 26, 2111-2121. doi: 10.1081/PLN- 120024268

Balk, J., and Lobréaux, S. (2005). Biogenesis of iron-sulfur proteins in plants. Trends Plant Sci. 10, 324-331. doi: 10.1016/j.tplants.2005.05.002

Balk, J., and Pilon, M. (2011). Ancient and essential: the assembly of iron-sulfur clusters in plants. Trends Plant Sci. 16, 218-226. doi: 10.1016/j.tplants.2010. 12.006

Balk, J., and Schaedler, T. A. (2014). Iron cofactor assembly in plants. Annu. Rev. Plant Biol. 65, 125-153. doi: 10.1146/annurev-arplant-050213-035759

Bartucca, M. L., Celletti, S., Astolfi, S., Mimmo, T., Cesco, S., Panfili, I., et al. (2017a). Effect of three safeners on sulfur assimilation and iron deficiency response in barley (Hordeum vulgare) plants. Pest Manag. Sci. 73, 240-245. doi: $10.1002 /$ ps.4291

Bartucca, M. L., Celletti, S., Mimmo, T., Cesco, S., Astolfi, S., and Del Buono, D. (2017b). Terbuthylazine interferes with iron nutrition in maize (Zea mays) plants. Acta Physiol. Plant. 39:235. doi: 10.1007/s11738-017-2537-z

Beddington, J. (2010). Food security: contributions from science to a new and greener revolution. Philos. Trans. R. Soc. Lond. B Biol. Sci. 365, 61-71. doi: 10.1098/rstb.2009.0201

Bouranis, D. L., Chorianopoulou, S. N., Protonotarios, V. E., Siyiannis, V. F., Hopkins, L., and Hawkesford, M. J. (2003). Leaf responses of young iron-inefficient maize plants to sulfur deprivation. J. Plant Nutr. 26, 11891202. doi: 10.1081/PLN-120020364

Briat, J.-F. (2009). "Mechanisms of iron homeostasis in plants and their regulations," in Proceedings of the International Plant Nutrition Colloquium XVI, Davis, CA.

Briat, J.-F., Curie, C., and Gaymard, F. (2007). Iron utilization and metabolism in plants. Curr. Opin. Plant Biol. 10, 276-282. doi: 10.1016/j.pbi.2007.04.003

Buchner, P., Takahashi, H., and Hawkesford, M. J. (2004). Plant sulphate transporters: co-ordination of uptake, intracellular and long-distance transport. J. Exp. Bot. 55, 1765-1773. doi: 10.1093/jxb/erh206

Bürstenbinder, K., Rzewuski, G., Wirtz, M., Hell, R., and Sauter, M. (2007). The role of methionine recycling for ethylene synthesis in Arabidopsis. Plant J. 49, 238-249. doi: 10.1111/j.1365-313X.2006.02942.X

Celletti, S., Paolacci, A. R., Mimmo, T., Pii, Y., Cesco, S., Ciaffi, M., et al. (2016a). The effect of excess sulfate supply on iron accumulation in three graminaceous plants at the early vegetative phase. Environ. Exp. Bot. 128, 31-38. doi: 10.1016/ j.envexpbot.2016.04.004

Celletti, S., Pii, Y., Mimmo, T., Cesco, S., and Astolfi, S. (2016b). The characterization of the adaptive responses of durum wheat to different $\mathrm{Fe}$ availability highlights an optimum Fe requirement threshold. Plant Physiol. Biochem. 109, 300-307. doi: 10.1016/j.plaphy.2016.10.010

Ciaffi, M., Paolacci, A. R., Celletti, S., Catarcione, G., Kopriva, S., and Astolfi, S. (2013). Transcriptional and physiological changes in the $S$ assimilation pathway due to single or combined $\mathrm{S}$ and Fe deprivation in durum wheat (Triticum durum L.) seedlings. J. Exp. Bot. 64, 1663-1675. doi: 10.1093/jxb/ert027

Clarkson, D., Hawkesford, M., and Davidian, J. (1993). "Membrane and longdistance transport of sulfate," in Sulphur Metabolism in Higher Plants, eds W. J. Cram, L. J. DeKok, I. Stulen, C. Brunold, H. Rennenberg, and W. E. Rauser (The Hague: SPB Academic Publishing), 3-19.

Coppa, E., Celletti, S., Pii, Y., Mimmo, T., Cesco, S., and Astolfi, S. (2018). Revisiting Fe/S interplay in tomato: a split-root approach to study the systemic and local responses. Plant Sci. 276, 134-142. doi: 10.1016/j.plantsci.2018. 08.015

Corbineau, F., Xia, Q., Bailly, C., and El-Maarouf-Bouteau, H. (2014). Ethylene, a key factor in the regulation of seed dormancy. Front. Plant Sci. 5:539. doi: 10.3389/fpls.2014.00539

Courbet, G., Gallardo, K., Vigani, G., Brunel-Muguet, S., Trouverie, J., Salon, C., et al. (2019). Disentangling the complexity and diversity of crosstalk between sulfur and other mineral nutrients in cultivated plants. J. Exp. Bot. 70, 41834196. doi: 10.1093/jxb/erz214

Crawford, N., Kahn, M., Leustek, T., and Long, S. (2000). "Nitrogen and sulphur," in Biochemistry and Molecular Biology of Plants, eds B. Buchanan, W. Gruissem, and R. L. Jones (Rochville, MD: American Society of Plant Physiologists), 786-849.

Del Buono, D., Astolfi, S., Mimmo, T., Bartucca, M. L., Celletti, S., Ciaffi, M., et al. (2015). Effects of terbuthylazine on phytosiderophores release in iron deficient barley. Environ. Exp. Bot. 116, 32-38. doi: 10.1016/j.envexpbot.2015. 03.007

Douchkov, D., Herbik, A., Koch, G., Mock, H.-P., Melzer, M., Stephan, U. W., et al. (2002). Nicotianamine synthase: gene isolation, gene transfer and application for the manipulation of plant iron assimilation. Plant Soil 241, 115-119. doi: 10.1023/A:1016085828996

Dubeaux, G., Neveu, J., Zelazny, E., and Vert, G. (2018). Metal sensing by the IRT1 transporter-receptor orchestrates its own degradation and plant metal nutrition. Mol. Cell 69, 953-964.e5. doi: 10.1016/j.molcel.2018.02.009

Fageria, V. D. (2001). Nutrient interactions in crop plants. J. Plant Nutr. 24, 1269-1290. doi: 10.1081/PLN-100106981

FAO (2015). Food and Agriculture Organization of the United Nations (FAO) Prepared by Intergovernmental Technical Panel on Soils (ITPS). Status of the World's Soil Resources (SWSR) - Main Report. Rome: FAO.

Feldman-Salit, A., Veith, N., Wirtz, M., Hell, R., and Kummer, U. (2019). Distribution of control in the sulfur assimilation in Arabidopsis thaliana depends on environmental conditions. New Phytol. 222, 1392-1404. doi: 10. 1111/nph.15704

Guerinot, M. L., and Yi, Y. (1994). Iron: nutritious, noxious, and not readily available. Plant Physiol. 104, 815-820. doi: 10.1104/pp.104.3.815

Habtegebrial, K., and Singh, B. R. (2006). Effects of timing of nitrogen and sulphur fertilizers on yield, nitrogen, and sulphur contents of Tef (Eragrostis tef (Zucc.) Trotter). Nutr. Cycl. Agroecosyst. 75, 213-222. doi: 10.1007/s10705-0069028-8

Haneklaus, S., Bloem, E., and Schnug, E. (2008). "History of sulfur deficiency in crops," in Sulfer: A Missing Link between Soils, Crops, and Nutrition, Vol. 50, ed. J. Jez (Hoboken, NJ: John Wiley \& Sons, Ltd), 45-58.

Hatzfeld, Y., Lee, S., Lee, M., Leustek, T., and Saito, K. (2000). Functional characterization of a gene encoding a fourth ATP sulfurylase isoform from Arabidopsis thaliana. Gene 248, 51-58. doi: 10.1016/S0378-1119(00)00132-3

Hawkesford, M. J. (2000). Plant responses to sulphur deficiency and the genetic manipulation of sulphate transporters to improve S-utilization efficiency. J. Exp. Bot. 51, 131-138. doi: 10.1093/jxb/51.342.131

Hawkesford, M. J. (2003). Transporter gene families in plants: the sulphate transporter gene family - Redundancy or specialization? Physiol. Plant. 117, 155-163. doi: 10.1034/j.1399-3054.2003.00034.x

Hawkesford, M. J., and De Kok, L. J. (2006). Managing sulphur metabolism in plants. Plant Cell Environ. 29, 382-395. doi: 10.1111/j.1365-3040.2005.01470.x

Hawkesford, M. J., Kopriva, S., and De Kok, L. J. (2014). Nutrient Use Efficiency in Plants: Concepts and Approaches, eds M. J. Hawkesford, S. Kopriva, and L. J. De Kok (Basingstoke: Springer Nature).

Hesse, H., and Hoefgen, R. (2003). Molecular aspects of methionine biosynthesis. Trends Plant Sci. 8, 259-262. doi: 10.1016/S1360-1385(03)00107-9

Hoefgen, R., and Hesse, H. (2007). "Sulfur in plants as part of a metabolic network," in Sulfur in Plants An Ecological Perspective. Plant Ecophysiology, eds M. J. Hawkesford and L. J. De Kok (Dordrecht: Springer), 107-142. doi: 10.1007/9781-4020-5887-5_6

Iqbal, N., Masood, A., Khan, M. I. R., Asgher, M., Fatma, M., and Khan, N. A. (2013). Cross-talk between sulfur assimilation and ethylene signaling in plants. Plant Signal. Behav. 8, 104-112. doi: 10.4161/psb.22478

Ivanov, R., Brumbarova, T., Blum, A., Jantke, A. M., Fink-Straube, C., and Bauer, P. (2014). SORTING NEXIN1 is required for modulating the trafficking and stability of the Arabidopsis IRON-REGULATED TRANSPORTER1. Plant Cell 26, 1294-1307. doi: 10.1105/tpc.113.116244

Jobe, T. O., Zenzen, I., Rahimzadeh Karvansara, P., and Kopriva, S. (2019). Integration of sulfate assimilation with carbon and nitrogen metabolism in transition from C3 to C4 photosynthesis. J. Exp. Bot. 70, 4211-4221. doi: 10. 1093/jxb/erz250

Kalmbacher, R. S., Ezenwa, I. V., Arthington, J. D., and Martin, F. G. (2005). Sulfur fertilization of bahiagrass with varying levels of nitrogen fertilization on a florida spodosol. Agron. J. 97, 661-667. doi: 10.2134/agronj2004. 0006

Khan, N. A., Asgher, M., Per, T. S., Masood, A., Fatma, M., and Khan, M. I. R. (2016). Ethylene potentiates sulfur-mediated reversal of cadmium inhibited 
photosynthetic responses in mustard. Front. Plant Sci. 7:1628. doi: 10.3389/fpls. 2016.01628

Khan, N. A., Khan, M. I. R., Ferrante, A., and Poor, P. (2017). Editorial: ethylene: a key regulatory molecule in plants. Front. Plant Sci. 8:1782. doi: 10.3389/fpls. 2017.01782

Kim, S. A., and Guerinot, M. L. (2007). Mining iron: Iron uptake and transport in plants. FEBS Lett. 581, 2273-2280. doi: 10.1016/j.febslet.2007.04.043

Klein, M., and Papenbrock, J. (2004). The multi-protein family of Arabidopsis sulphotransferases and their relatives in other plant species. $J$ Exp Bot 55, 1809-1820. doi: 10.1093/jxb/erh183

Kobayashi, T., and Nishizawa, N. K. (2012). Iron uptake, translocation, and regulation in higher plants. Annu. Rev. Plant Biol. 63, 131-152. doi: 10.1146/ annurev-arplant-042811-105522

Kopriva, S. (2006). Regulation of sulfate assimilation in Arabidopsis and beyond. Ann. Bot. 97, 479-495. doi: 10.1093/aob/mcl006

Koprivova, A., and Kopriva, S. (2014). Molecular mechanisms of regulation of sulfate assimilation: first steps on a long road. Front. Plant Sci. 5:589. doi: 10.3389/fpls.2014.00589

Koprivova, A., Suter, M., Op den Camp, R., Brunold, C., and Kopriva, S. (2000). Regulation of sulfate assimilation by nitrogen in Arabidopsis. Plant Physiol. 122, 737-746. doi: 10.1104/pp.122.3.737

Kuwajima, K., and Kawai, S. (1997). "Relationship between sulfur metabolism and biosynthesis of phytosiderophores in barley roots," in Plant Nutrition for Sustainable Food Production and Environment: Developments in Plant and Soil Sciences, Vol. 78, eds T. Ando, K. Fujita, T. Mae, H. Matsumoto, S. Mori, and J. Sekiya (Dordrecht: Springer), 285-286.

Lal, R. (2015). The soil-peace nexus: our common future. Soil Sci. Plant Nutr. 61, 566-578. doi: 10.1080/00380768.2015.1065166

Lejay, L., Wirth, J., Pervent, M., Cross, J. M.-F., Tillard, P., and Gojon, A. (2008). Oxidative pentose phosphate pathway-dependent sugar sensing as a mechanism for regulation of root ion transporters by photosynthesis. Plant Physiol. 146, 2036-2053. doi: 10.1104/pp.107.114710

Leustek, T., Martin, M. N., Bick, J.-A., and Davies, J. P. (2000). Pathways and regulation of sulfur metabolism revealed through molecular and genetic studies. Annu. Rev. Plant Biol. 51, 141-165. doi: 10.1146/annurev.arplant.51.1.141

Lewandowska, M., and Sirko, A. (2008). Recent advances in understanding plant response to sulfur-deficiency stress. Acta Biochim. Pol. 55, 457-471. doi: 10. 18388/abp.2008_3051

$\mathrm{Li}, \mathrm{X}$., and $\mathrm{Li}, \mathrm{C}$. (2004). Is ethylene involved in regulation of root ferric reductase activity of dicotyledonous species under iron deficiency? Plant Soil 261, 147153. doi: 10.1023/B:PLSO.0000035536.79001.60

López-Millán, A. F., Duy, D., and Philippar, K. (2016). Chloroplast iron transport proteins - Function and impact on plant physiology. Front. Plant Sci. 7:178. doi: $10.3389 /$ fpls.2016.00178

Lucena, C., Romera, F. J., García, M. J., Alcántara, E., and Pérez-Vicente, R. (2015). Ethylene participates in the regulation of Fe deficiency responses in strategy I plants and in rice. Front. Plant Sci. 6:1056. doi: 10.3389/fpls.2015. 01056

Ma, C., Chen, Y., Ding, S., Li, Z., Shi, W. G., Zhang, Y., et al. (2018). Sulfur nutrition stimulates lead accumulation and alleviates its toxicity in Populus deltoides. Tree Physiol. 38, 1724-1741. doi: 10.1093/treephys/tpy069

Mapolelo, D. T., Zhang, B., Randeniya, S., Albetel, A. N., Li, H., Couturier, J., et al. (2013). Monothiol glutaredoxins and A-type proteins: partners in Fe-S cluster trafficking. Dalt. Trans. 42, 3107-3115. doi: 10.1039/c2dt32263c

Marschner, P. (2012). Marschner's Mineral Nutrition of Higher Plants, ed. P. Marschner (Amsterdam: Elselvier Ltd.).

Mathot, M., Thélier-Huché, L., and Lambert, R. (2009). Sulphur and nitrogen content as sulphur deficiency indicator for grasses. Eur. J. Agron. 30, 172-176. doi: 10.1016/j.eja.2008.09.004

McGrath, S. P., and Zhao, F. J. (1995). A risk assessment of sulphur deficiency in cereals using soil and atmospheric deposition data. Soil Use Manag. 11, 110-114. doi: 10.1111/j.1475-2743.1995.tb00507.x

McGrath, S. P., Zhao, F. J., and Withers, P. J. A. (1996). "Development of sulphur deficiency in crops and its treatment," in Proceedings of the Fertiliser Society (Peterborough: The Fertiliser Society).

Mendoza-Cózatl, D. G., Gokul, A., Carelse, M. F., Jobe, T. O., Long, T. A., and Keyster, M. (2019). Keep talking: crosstalk between iron and sulfur networks fine-tunes growth and development to promote survival under iron limitation. J. Exp. Bot. 70, 4197-4210. doi: 10.1093/jxb/erz290

Mengel, K. (1994). Iron availability in plant tissues-iron chlorosis on calcareous soils. Plant Soil 165, 275-283. doi: 10.1007/BF0000 8070

Molassiotis, A., Therios, I., Dimassi, K., Diamantidis, G., and Chatzissavvidis, C. (2005). Induction of $\mathrm{Fe}$ (III)-chelate reductase activity by ethylene and salicylic acid in iron-deficient peach rootstock explants. J. Plant Nutr. 28, 669-682. doi: 10.1081/PLN-200052641

Mori, S. (1999). Iron acquisition by plants. Curr. Opin. Plant Biol. 2, 250-253. doi: 10.1016/S1369-5266(99)80043-0

Mori, S., and Nishizawa, N. (1987). Methionine as a dominant precursor of phytosiderophores in graminaceae plants. Plant Cell Physiol. 28, 1081-1092. doi: 10.1093/oxfordjournals.pcp.a077388

Morrissey, J., and Guerinot, M. L. (2009). Iron uptake and transport in plants: the good, the bad, and the ionome. Chem. Rev. 109, 4553-4567. doi: 10.1021/ cr900112r

Muneer, S., Lee, B.-R., Kim, K.-Y., Park, S.-H., Zhang, Q., and Kim, T.-H. (2014). Involvement of sulphur nutrition in modulating iron deficiency responses in photosynthetic organelles of oilseed rape (Brassica napus L.). Photosynth. Res. 119, 319-329. doi: 10.1007/s11120-013-9953-8

Murata, Y., Ma, J. F., Yamaji, N., Ueno, D., Nomoto, K., and Iwashita, T. (2006). A specific transporter for iron(III)-phytosiderophore in barley roots. Plant J. 46, 563-572. doi: 10.1111/j.1365-313X.2006.02714.x

Nikolic, M., and Kastori, R. (2000). Effect of bicarbonate and Fe supply on Fe nutrition of grapevine. J. Plant Nutr. 23, 1619-1627. doi: 10.1080/ 01904160009382128

North, K., and Kopriva, S. (2007). Probing natural variation and nutrient use efficiency in Arabidopsis. Comp. Biochem. Physiol. Part A Mol. Integr. Physiol. 146:S248. doi: 10.1016/j.cbpa.2007.01.577

Pala, Z. R., Saxena, V., Saggu, G. S., and Garg, S. (2018). Recent advances in the [FeS] cluster biogenesis (SUF) pathway functional in the apicoplast of plasmodium. Trends Parasitol. 34, 800-809. doi: 10.1016/j.pt.2018.05.010

Paolacci, A. R., Celletti, S., Catarcione, G., Hawkesford, M. J., Astolfi, S., and Ciaffi, M. (2014). Iron deprivation results in a rapid but not sustained increase of the expression of genes involved in iron metabolism and sulfate uptake in tomato (Solanum lycopersicum L.) seedlings. J. Integr. Plant Biol. 56, 88-100. doi: 10.1111/jipb.12110

Pii, Y., Cesco, S., and Mimmo, T. (2015). Shoot ionome to predict the synergism and antagonism between nutrients as affected by substrate and physiological status. Plant Physiol. Biochem. 94, 48-56. doi: 10.1016/j.plaphy.2015. 05.002

Pilbeam, D. J. (2015). Breeding crops for improved mineral nutrition under climate change conditions. J. Exp. Bot. 66, 3511-3521. doi: 10.1093/jxb/eru539

Ravanel, S., Gakière, B., Job, D., and Douce, R. (1998). Cystathionine $\gamma$-synthase from Arabidopsis thaliana: purification and biochemical characterization of the recombinant enzyme overexpressed in Escherichia coli. Biochem. J. 331, 639-648. doi: 10.1042/bj3310639

Rietra, R. P. J. J., Heinen, M., Dimkpa, C. O., and Bindraban, P. S. (2017). Effects of nutrient antagonism and synergism on yield and fertilizer use efficiency. Commun. Soil Sci. Plant Anal. 48, 1895-1920. doi: 10.1080/00103624.2017. 1407429

Robe, K., Gao, F., Bonillo, P., Tissot, N., Gaymard, F., Fourcroy, P., et al. (2020). Sulphur availability modulates Arabidopsis thaliana responses to iron deficiency. PLoS One 15:e0237998. doi: 10.1371/journal.pone.02 37998

Romera, F. J., and Alcántara, E. (2004). Ethylene involvement in the regulation of Fe-deficiency stress responses by Strategy I plants. Funct. Plant Biol. 31, 315-328. doi: 10.1071/FP03165

Romera, F. J., Alcantara, E., and De La Guardia, M. D. (1999). Ethylene production by $\mathrm{Fe}$-deficient roots and its involvement in the regulation of Fe-deficiency stress responses by Strategy I plants. Ann. Bot. 83, 51-55. doi: 10.1006/anbo. 1998.0793

Rudolph, A., Becker, R., Scholz, G., Procházka, Z., Toman, J., Macek, T., et al. (1985). The occurrence of the amino acid nicotianamine in plants and microorganisms. A reinvestigation. Biochem. Physiol. Pflanz. 180, 557-563. doi: 10.1016/S0015-3796(85)80036-6 
Saito, K. (2000). Regulation of sulfate transport and synthesis of sulfur-containing amino acids. Curr. Opin. Plant Biol. 3, 188-195. doi: 10.1016/s1369-5266(00) 80064-3

Salvagiotti, F., Castellarín, J. M., Miralles, D. J., and Pedrol, H. M. (2009). Sulfur fertilization improves nitrogen use efficiency in wheat by increasing nitrogen uptake. F. Crop. Res. 113, 170-177. doi: 10.1016/j.fcr.2009.05.003

Scherr, S. J. (1999). Soil degradation: a threat to developing-country food security by 2020?. Paper Presented at the 2020 Vision Discussion Papers 27 (Washington, DC: International Food Policy Research Institute (IFPRI)).

Schwarzländer, M., König, A.-C., Sweetlove, L. J., and Finkemeier, I. (2012). The impact of impaired mitochondrial function on retrograde signalling: a metaanalysis of transcriptomic responses. J. Exp. Bot. 63, 1735-1750. doi: 10.1093/ jxb/err374

Shin, L. J., Lo, J. C., Chen, G. H., Callis, J., Fu, H., and Yeh, K. C. (2013). IRT1 degradation factor1, a ring E3 Ubiquitin ligase, regulates the degradation of iron-regulated transporter1 in Arabidopsis. Plant Cell 25, 3039-3051. doi: 10. 1105/tpc.113.115212

Stehling, O., and Lill, R. (2013). The role of mitochondria in cellular iron-sulfur protein biogenesis: mechanisms, connected processes, and diseases. Cold Spring Harb. Perspect. Biol. 5:a011312. doi: 10.1101/cshperspect.a011312

Sugimoto, K., Tsuzuki, M., and Sato, N. (2010). Regulation of synthesis and degradation of a sulfolipid under sulfur-starved conditions and its physiological significance in Chlamydomonas reinhardtii. New Phytol. 185, 676-686. doi: 10.1111/j.1469-8137.2009.03115.x

Takagi, S.-I. (1976). Naturally occurring iron. Chelating compounds in oat- and rice-rootwashings 1 . activity measurement and preliminary characterization. Soil Sci. Plant Nutr. 22, 423-433. doi: 10.1080/00380768.1976.10433004

Takahashi, H., Kopriva, S., Giordano, M., Saito, K., and Hell, R. (2011). Sulfur assimilation in photosynthetic organisms: molecular functions and regulations of transporters and assimilatory enzymes. Annu. Rev. Plant Biol. 62, 157-184. doi: 10.1146/annurev-arplant-042110-103921

Takahashi, M., Terada, Y., Nakai, I., Nakanishi, H., Yoshimura, E., Mori, S., et al. (2003). Role of nicotianamine in the intracellular delivery of metals and plant reproductive development. Plant Cell 15, 1263-1280. doi: 10.1105/tpc.010256

Tilman, D., Cassman, K. G., Matson, P. A., Naylor, R., and Polasky, S. (2002). Agricultural sustainability and intensive production practices. Nature 418, 671-677. doi: 10.1038/nature01014

Vigani, G., and Briat, J. F. (2016). Impairment of respiratory chain under nutrient deficiency in plants: does it play a role in the regulation of iron and sulfur responsive genes? Front. Plant Sci. 6:1185. doi: 10.3389/fpls.2015.01185

Vigani, G., and Hanikenne, M. (2018). "Metal homeostasis in plant mitochondria," in Annual Plant Reviews Online, ed. D. C. Logan (Chichester: John Wiley \& Sons, Ltd), 111-142. doi: 10.1002/9781119312994.apr0547

Vigani, G., and Murgia, I. (2018). Iron-requiring enzymes in the spotlight of oxygen. Trends Plant Sci. 23, 874-882. doi: 10.1016/j.tplants.2018.07.005

Vigani, G., Pii, Y., Celletti, S., Maver, M., Mimmo, T., Cesco, S., et al. (2018). Mitochondria dysfunctions under Fe and S deficiency: is citric acid involved in the regulation of adaptive responses? Plant Physiol. Biochem. 126, 86-96. doi: 10.1016/j.plaphy.2018.02.022

Von Wirén, N., Klair, S., Bansal, S., Briat, J.-F., Khodr, H., Shioiri, T., et al. (1999). Nicotianamine chelates both Fe(III) and Fe(II) implications for metal transport in plants. Plant Physiol. 119, 1107-1114. doi: 10.1104/pp.119.3.1107

Wang, K. L. C., Li, H., and Ecker, J. R. (2002). Ethylene biosynthesis and signaling networks. Plant Cell 14, S131-S151. doi: 10.1105/tpc.001768
Wawrzynska, A., Moniuszko, G., and Sirko, A. (2015). Links between ethylene and sulfur nutrition - A regulatory interplay or just metabolite association? Front. Plant Sci. 6:1053. doi: 10.3389/fpls.2015.01053

Wawrzyñska, A., and Sirko, A. (2020). The role of selective protein degradation in the regulation of iron and sulfur homeostasis in plants. Int. J. Mol. Sci. 21:2771. doi: 10.3390/ijms21082771

Wu, Z., Naveed, S., Zhang, C., and Ge, Y. (2020). Adequate supply of sulfur simultaneously enhances iron uptake and reduces cadmium accumulation in rice grown in hydroponic culture. Environ. Pollut. 262, 114327. doi: 10.1016/j. envpol.2020.114327

Wu, Z., Zhang, C., Dai, C., and Ge, Y. (2015). Sufficient sulfur supply promotes seedling growth, alleviates oxidation stress, and regulates iron uptake and translocation in rice. Biol. Plant. 59, 788-792. doi: 10.1007/s10535-0150554-6

Xie, K., Cakmak, I., Wang, S., Zhang, F., and Guo, S. (2021). Synergistic and antagonistic interactions between potassium and magnesium in higher plants. Crop J. 9, 249-256. doi: 10.1016/j.cj.2020.10.005

Yamaguchi, C., Takimoto, Y., Ohkama-Ohtsu, N., Hokura, A., Shinano, T., Nakamura, T., et al. (2016). Effects of cadmium treatment on the uptake and translocation of sulfate in Arabidopsis thaliana. Plant Cell Physiol. 57, 2353-2366. doi: 10.1093/pcp/pcw156

Yang, J., Duan, G., Li, C., Liu, L., Han, G., Zhang, Y., et al. (2019). The crosstalks between jasmonic acid and other plant hormone signaling highlight the involvement of jasmonic acid as a core component in plant response to biotic and abiotic stresses. Front. Plant Sci. 10:1349. doi: 10.3389/fpls.2019. 01349

Zamboni, A., Celletti, S., Zenoni, S., Astolfi, S., and Varanini, Z. (2017). Root physiological and transcriptional response to single and combined $S$ and $\mathrm{Fe}$ deficiency in durum wheat. Environ. Exp. Bot. 143, 172-184. doi: 10.1016/j. envexpbot.2017.09.002

Zhao, F. J., Hawkesford, M. J., and McGrath, S. P. (1999). Sulphur assimilation and effects on yield and quality of wheat. J. Cereal Sci. 30, 1-17. doi: 10.1006/jcrs. 1998.0241

Zuchi, S., Cesco, S., and Astolfi, S. (2012). High S supply improves Fe accumulation in durum wheat plants grown under Fe limitation. Environ. Exp. Bot. 77, 25-32. doi: 10.1016/j.envexpbot.2011.11.001

Zuchi, S., Cesco, S., Varanini, Z., Pinton, R., and Astolfi, S. (2009). Sulphur deprivation limits Fe-deficiency responses in tomato plants. Planta 230, 85-94. doi: 10.1007/s00425-009-0919-1

Zuchi, S., Watanabe, M., Hubberten, H. M. H.-M., Bromke, M., Osorio, S., Fernie, A. R., et al. (2015). The interplay between sulfur and iron nutrition in tomato. Plant Physiol. 169, 2624-2639. doi: 10.1104/pp.15. 00995

Conflict of Interest: The authors declare that the research was conducted in the absence of any commercial or financial relationships that could be construed as a potential conflict of interest.

Copyright (c) 2021 Astolfi, Celletti, Vigani, Mimmo and Cesco. This is an open-access article distributed under the terms of the Creative Commons Attribution License (CC BY). The use, distribution or reproduction in other forums is permitted, provided the original author(s) and the copyright owner(s) are credited and that the original publication in this journal is cited, in accordance with accepted academic practice. No use, distribution or reproduction is permitted which does not comply with these terms. 